\title{
The Slow Road to Big Change: \\ Extending the Advocacy Coalition Framework with the Theory of Gradual, Institutional Change
}

\author{
Leanne Giordono* \\ Oregon State University \\ School of Social and Behavioral Health Sciences
}

*Author contact information: giordonl@oregonstate.edu. Unpublished manuscript; please do not cite or circulate without permission from author. 


\begin{abstract}
The Advocacy Coalition Framework is a policy process framework that explains subsystem-level policy change as a function of competition by advocacy coalitions. The ACF's theory of policy change expects that abrupt policy changes are more likely to reflect major change, while incremental developments are more likely to yield minor changes. While the ACF does not explicitly preclude the possibility of major change occurring over a long time horizon via incremental developments, the theoretical pathways do not readily accommodate or explain such cases. In contrast, the theory of Gradual Institutional Change (GIC) offers a typology associated with gradual (incremental), transformative (major) change, as well as an underlying theory to account for such changes, building on distinctions between the process of change (incremental or abrupt) and the result of change (discontinuity or continuity). The GIC identifies four "modes” of institutional change (i.e., displacement, layering, conversion and drift), and suggests that when major change can occur over a shorter time frame, it is analogous to the non-incremental and discontinuous process typically examined by the ACF. The GIC further posits that incremental, transformative (major) change is influenced by similar forces as those that influence nonincremental change, such as political context, key policy actors, and institutions. The GIC thus offers an opportunity to apply concepts of gradual, institutional change in the context of the ACF theory of policy change. Given these theoretical and empirical observations, this study has two objectives: 1) to identify strategies for using concepts from the GIC in the context of the ACF; and 2) to illustrate the added value of an extended framework. The study begins with a description of the theoretical frameworks, including motivation and operationalization of the proposed integration, followed by an illustration applied to the disability policy subsystem in Washington State. The study responds to recent calls for more integration of the policy process and comparative politics literatures, and follows in the tracks of other innovations that build on and/or extend the Advocacy Coalition Framework with insights from other theoretical traditions. The extension is expected to increase the scope and relevance of both theories and offer broader opportunities for empirical application.
\end{abstract}

Key Words: Advocacy Coalition Framework, Theory of Gradual Institutional Change, policy change, advocacy, institutions 


\section{Introduction and Rationale}

The ACF is a policy process framework developed by Sabatier and Jenkins-Smith (1993) that explains subsystem-level policy change as a function of competition by advocacy coalitions. The ACF's theory of policy change defines major policy changes as those exhibiting "significant shifts in the direction or goals of the subsystem" (Jenkins-Smith et al. 2017, 145), while minor policy changes primarily reflect a change in the means of achieving acknowledged goals (Jenkins-Smith et al. 2017, 145; Sabatier and Jenkins-Smith 1993). ${ }^{1}$ The ACF expects that abrupt policy changes are more likely to reflect major change, while incremental developments, such as policy-oriented learning, are more likely to yield minor changes (Jenkins-Smith et al. 2017). While the ACF does not explicitly preclude the possibility of major change occurring over a long time horizon via incremental developments, the theoretical pathways do not readily accommodate or explain such cases.

In contrast, Mahoney and Thelen (2009) offer both a typology associated with gradual (incremental), transformative (major) change, as well as an underlying theory to account for such changes. They build on Streeck and Thelen's (2005) earlier distinction between the process of change (incremental or abrupt) and the result of change (discontinuity or continuity), and their identification of four "modes" of institutional change (i.e., displacement, layering, conversion and drift) to develop a Theory of Gradual Institutional Change (GIC). The GIC posits specific configurations of rule changes (i.e., removal of old rules, neglect of old rules, changed enactment, and introduction of new rules) associated with each type of change. Importantly, Mahoney and Thelen (2009) suggest when displacement occurs over a shorter time frame, it is essentially analogous to the more abrupt and discontinuous process typically examined by traditional change frameworks.

The GIC thus offers an opportunity to apply concepts of gradual, institutional change in the context of the ACF, which would expand its scope and relevance, as well as respond to recent calls to explore potential integration of the policy process and comparative politics literatures (e.g., John 2017; Tosun and Workman 2017). Given these theoretical and empirical observations, this study has two objectives: 1) to identify strategies for using concepts from the

\footnotetext{
${ }^{1}$ Following (Koebele 2019; Pierce et al. 2017), I distinguish between the broader Advocacy Coalition Framework and the three theoretical streams focused on 1) advocacy coalitions; 2) policy-oriented learning and 3) policy change. This study is primarily focused on ACF policy change theory.
} 
GIC in the context of the ACF; and 2) to illustrate the added value of an extended framework. The study begins with a description of the theoretical frameworks, including motivation and operationalization of the proposed integration, followed by an illustration applied to the disability policy subsystem in Washington State. The subsequent discussion includes both theoretical and policy implications. The study finds that the proposed extension of the ACF provides a richer explanatory framework for certain types of major policy change, especially cases that exhibit signs of having transitioned from earlier incremental change to more abrupt change years later. This is likely to be particularly valuable when applied to subsystems that can accommodate a layered, dual-option system (i.e., two or more competing policy options), such as service-based systems. Although the GIC is a newer framework, Mahoney and Thelen’s (2009) description of the framework has generated 130 citations across a variety of policy fields (e.g., social, economic, energy, etc). ${ }^{2}$

The proposed extension is accompanied by an illustration using a case of changes to disability-focused Day Habilitation and Employment policy in Washington State. Recent comparative work by Giordono (2019b, 2019a) applies the Advocacy Coalition Framework (ACF) to two states, Washington and Pennsylvania, which both achieved abrupt and major policy change with markedly different timing. Giordono (2019a) finds evidence of advocacy coalition in the subsystem, despite the low salience nature of the policy domain, while. Giordono (2019b), identifies several conditions leading to major policy change in both states, including subsystem events, bureaucratic advocacy and heightened political attention, as predicted by the ACF. However, the study also identifies one condition, coalition defection by service providers, which is associated with the timing of policy change. While coalition defection is a key condition of major policy change in the case of early policy adoption (Washington), it is not a condition of later major policy change (Pennsylvania). Giordono (2019b) notes that in Washington, coalition defection is likely to have been associated with earlier, incremental policy changes in the 1980s and 1990s.

The illustration describes incremental public policy changes (e.g., rule changes and investments) in a dual-option system that preceded differential changes to coalition membership over time, culminating in coalition defection and setting the stage for more abrupt, major policy change that places restrictions on previous options. The illustration demonstrates the relevance of

\footnotetext{
${ }^{2}$ Based on a World of Science Citation Reference Search conducted on March 22, 2019.
} 
GIC concepts and suggests that incremental policy change may be an important antecedent to abrupt change under certain conditions. This study highlights the potential for early policy decisions to set a differential course for major policy change, as well as the signals, including coalition defection and bureaucratic advocacy, that may foreshadow the transition from a layered, or dual-service system, to one that favors a single option.

This study follows in the footsteps of multiple efforts to integrate or otherwise extend the applicability of the ACF to accommodate new theoretical insights and empirical evidence. The Narrative Policy Framework (McBeth et al. 2007; Shanahan, Jones, and McBeth 2011) and Conflict Policy Framework (Weible and Heikkila 2017), for example, represent full-fledged theoretical innovations that lean heavily on ACF foundations, while contributions by Kübler (2001) and Koebele (2019), introduce extensions of the ACF based on theoretical insights from the social movements and collaborative governance literatures.

\section{Theoretical Alignment}

The ACF is a longstanding framework that has been tested in multiple contexts to explain dramatic policy change (i.e., discontinuous result, abrupt process). The GIC is a more recent theoretical contribution that focuses on gradual, transformative change (i.e., discontinuous result, incremental process), offering an opportunity to expand the traditional ACF focus on major change. This section describes both frameworks, identifies opportunities for integration, and addresses their epistemological compatibility.

\subsection{Advocacy Coalition Framework}

The ACF is a policy process framework developed by Sabatier and Jenkins-Smith (1993) that explains subsystem-level policy change as a function of competition by advocacy coalitions. According to the ACF, advocacy coalitions, which can include a variety of subsystem policy actors, form around a shared 3-tiered belief system (deep core, policy core and secondary) and coordinate to achieve their policy preferences (Jenkins-Smith et al. 2017; Sabatier and JenkinsSmith 1993). The ACF typically applies a binary typology of policy change including "major” and "minor" change, reflecting shifts in the subsystem goals (i.e., policy core aspects) and the means for achieving subsystem goals (i.e., secondary aspects), respectively (Sabatier and Jenkins-Smith 1993). The ACF also distinguishes between incremental and nonincremental policy change; while nonincremental change is the primary focus, the ACF acknowledges the 
possibility of incremental change (Jenkins-Smith et al. 2017). As shown in Figure 1, the ACF hypothesizes multiple pathways to major policy change, including: 1) external perturbations; 2) internal events; 3) policy-oriented learning; 4) negotiated agreement; and 5) hierarchical imposition (Jenkins-Smith et al. 2017).

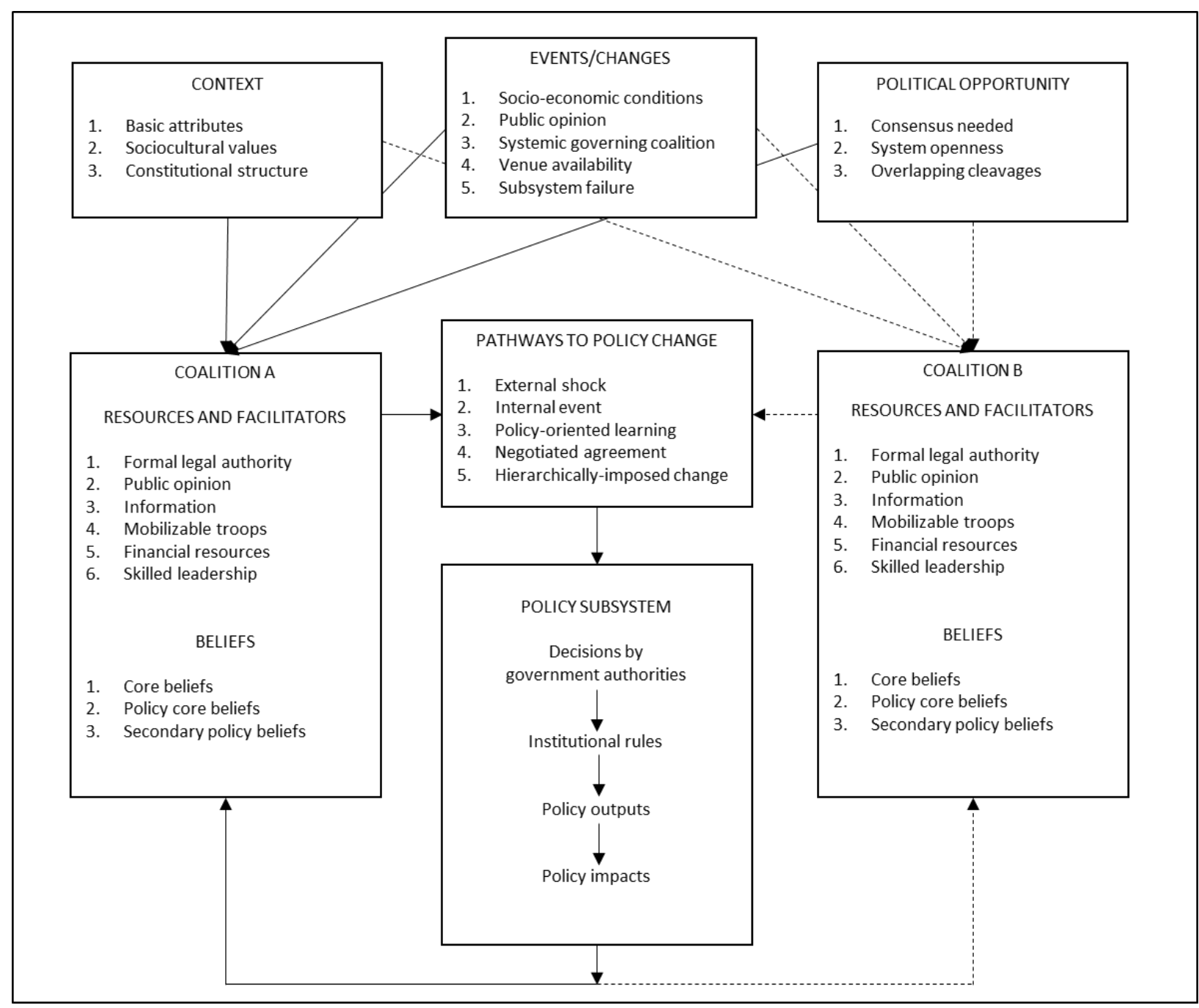

Figure 1: The Advocacy Coalition Framework, adapted from (2017)

All of these pathways are subject to subsystem conditions, including stable (contextual) parameters, long-term coalition opportunity structures and short-term constraints and resources, all of which act to influence coalitional beliefs, resources and strategies. While not explicitly hypothesized by the original ACF, Nohrstedt (2011) identifies three key causal mechanisms that are hypothesized to increase the likelihood of major policy change, including: 1) shifts in 
advocacy coalition membership; 2) redistribution of subsystem resources; and 3) opportunities to access new policy venues. The two major ACF policy change hypotheses are as follows:

Policy change hypothesis 1: Significant perturbations external to the subsystem, a significant perturbation internal to the subsystem, policy-oriented learning, negotiated agreement, or some combination thereof are necessary, but not sufficient, sources of change in the policy core attributes of a governmental program.

Policy change hypothesis 2: The policy core attributes of a government program in a specific jurisdiction will not be significantly revised as long as subsystem advocacy coalition that instated the program remains in power within that jurisdiction -- except when the change is imposed by a hierarchically superior jurisdiction.

The ACF also specifies theories of coalition advocacy formation and maintenance, as well as policy-oriented learning (Jenkins-Smith et al. 2017; Sabatier and Jenkins-Smith 1993)(Jenkins-Smith et al. 2017; Sabatier and Jenkins-Smith 1993). Policy-oriented learning is more likely to occur incrementally and serve as a source of minor policy change (Jenkins-Smith et al. 2017).

\subsection{Theory of Gradual Institutional Change}

Streeck and Thelen (2005) offer a typology of institutional change that moves beyond the incremental/non-incremental dichotomy, instead distinguishing four types of change based on the process of change (incremental/abrupt) and the results of change (continuity/ discontinuity). This typology describes four types of institutional change, including: 1) reproduction by adaptation (incremental and continuity); 2) survival and return (abrupt and continuity); 3) gradual transformation (incremental and discontinuity); and 4) breakdown and replacement (abrupt and discontinuity). The last type, breakdown and replacement, is the type of change typically associated with policy process frameworks. They further identify five "modes of gradual yet nevertheless transformative change”, including displacement, layering, conversion, drift and exhaustion.

Mahoney and Thelen (2009) subsequently describe the first four modes with respect to configurations of rule changes (removal of old rules, neglect of old rules, changed enactment, and introduction of new rules) that are associated with each type of change. Displacement involves the removal of old rules and the introduction of new rules; displacement that occurs 
abruptly is a more traditional theoretical focus. Layering occurs with the introduction of new rules without changing old rules, while drift involves the neglect, changed interpretation or modified enforcement of old rules without introducing new rules or removing old rules. Finally, conversion occurs when old rules are interpreted or enforced in new ways in the absence of any formal rule changes. Figure 2 displays the GIC framework for explaining modes of institutional change.

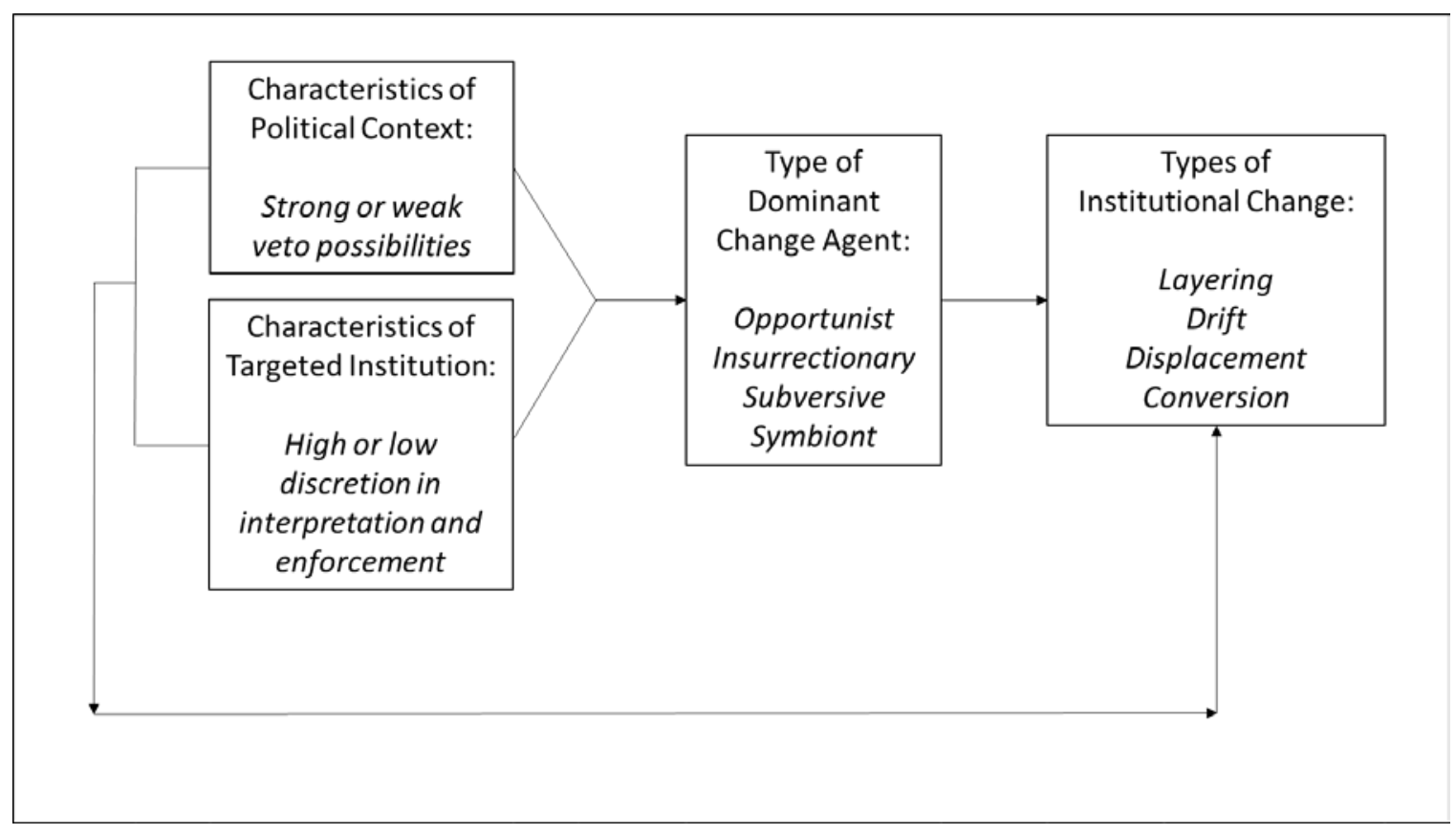

Figure 2: Framework for Explaining Modes of Institutional Change, adapted from Mahoney and Thelen (2009)

In addition to offering typological clarification, Mahoney and Thelen (2009) specify a Theory of Gradual Institutional Change (GIC), which is predicated on the idea that institutional change arises from distribution power struggles. As shown in Figure 3, the framework hypothesizes that different types of gradual, transformative change are associated with the characteristics of the political context (strong or weak veto possibilities) and characteristics of the targeted institution (low or high levels of discretion in interpretation/enforcement). Furthermore, they posit that change agents act as a driving force for change, and that the type of change agent (insurrectionary, opportunist, subversive or parasitic symbiont) varies according to the political and institutional context. 


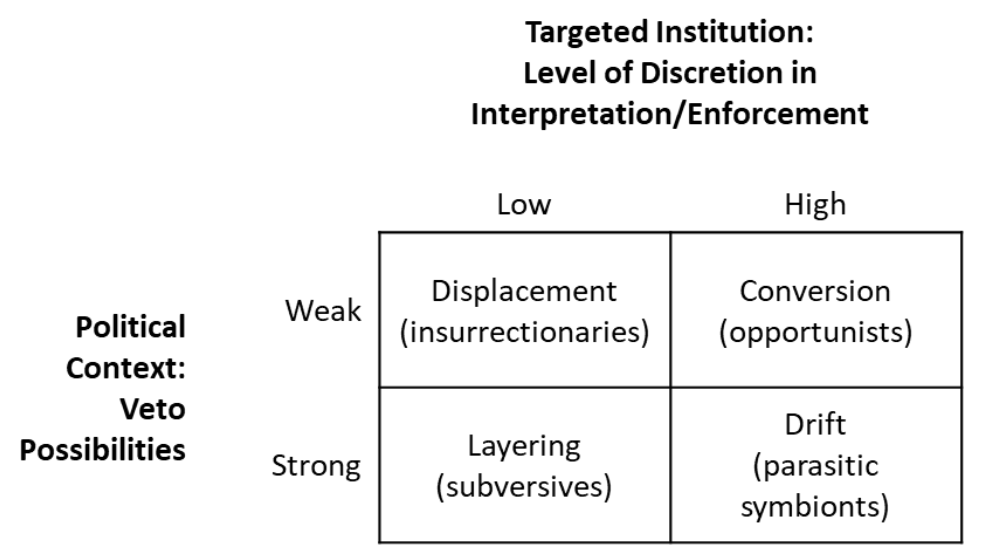

Figure 3: Institutional Change Types and Change Agents (in parens), adapted from Mahoney and Thelen (2009)

The GIC, therefore, explicitly acknowledges that both institutional characteristics and individual action may act in tandem to influence the mode of change. Importantly, Mahoney and Thelen (2009) note that displacement can occur over a short or a long time horizon. When major change occurs abruptly, it more closely resembles the type of change typically examined by theories of the policy process, underscoring the potential for the proposed theoretical extension.

\subsection{Conceptual Integration}

Extension of the ACF with GIC concepts involves modifications to expected 1) policy change typology; 2) pathways to policy change; 3) conceptual elements; and 4) causal mechanisms.

\section{Policy Change Typology}

Streeck and Thelen's (2005) framework of change is useful for comparing the frameworks, which exhibit complementary typologies of change. As shown in Figure 4, both frameworks describe policy change according to two main dimensions: 1) the discontinuity of the result; and 2) the nature of the policy process. However, they use different vocabulary to express similar concepts. Where the ACF labels discontinuous change as "major" change, with a focus on the change in policy core beliefs, the GIC describes such change as "transformative," with less emphasis on framework-specific content. Where the GIC uses the terms "gradual" and "abrupt" to describe time horizons of change, the ACF uses "incremental" and "nonincremental." Similarly, the frameworks place theoretical emphasis on different types of change. While the 
ACF emphasizes discontinuous change experienced nonincrementally, the GIC is primarily interested in explaining discontinuous change experienced incrementally.

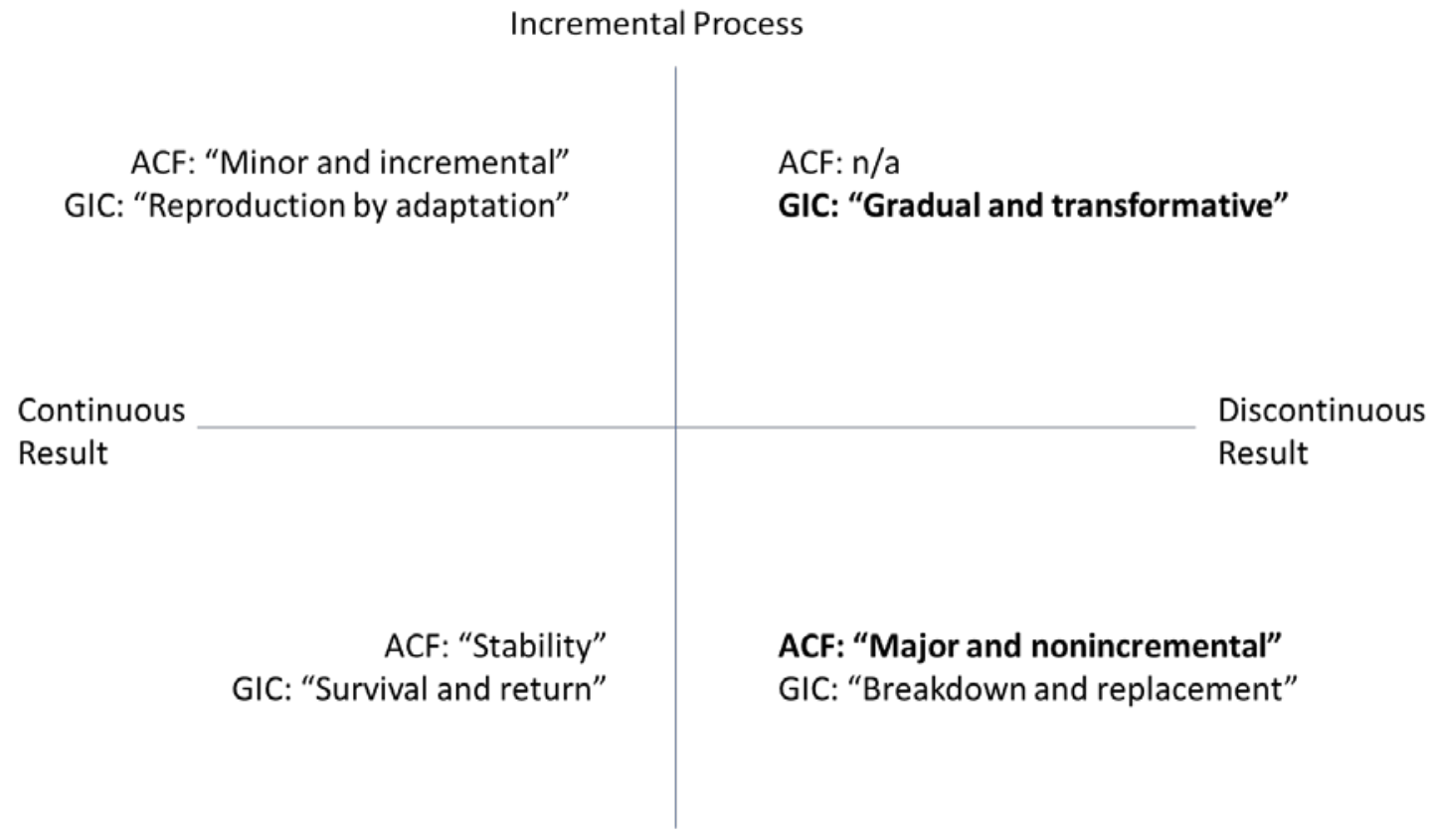

Nonincremental Process

Figure 4: ACF and GIC typologies of change (framework emphasis shown in bold)

$\underline{\text { Pathways to Policy Change }}$

The GIC suggests an alternative pathway to major policy change, marked by a long timehorizon, incremental change process, endogenous mechanisms and four main types of gradual, transformative change. As such, integration of the two frameworks suggests the following starting propositions:

Proposition 1a: Significant perturbations external to the subsystem, a significant perturbation internal to the subsystem, policy-oriented learning, negotiated agreement, gradual institutional policy change, or some combination thereof are necessary, but not sufficient, sources of change in the policy core attributes of a governmental program.

Proposition 1b: Gradual, transformative change away from the status quo increases the likelihood and degree of abrupt reform-oriented change in response to subsystem events.

Neither proposition directly contradicts current ACF propositions, given that the ACF acknowledges the possibility of major change resulting from both internal events, (likely to be 
endogenous). However, they add the potential for a hybrid or two-stage pathway to major policy change, involving incremental policy change that yields conditions necessary for more abrupt change.

\section{Conceptual Elements}

The GIC hypothesizes two key conditions that matter to the type of change likely to emerge: political context and characteristics of the targeted institution. The GIC specification of political context relates specifically to the possibility of veto by "actors who have access to institutional or extrainstitutional means of blocking change” (Mahoney and Thelen 2009, 19). This constraint resembles the ACF's identification of “degree of consensus needed” as an important long-term opportunity structure in response to comparative work (Sabatier and Weible 2007). However, the GIC offers a broader view of that concept than the ACF, which focuses primarily on differences between the national-level political systems (e.g., pluralist, corporatist, etc.). Instead, the GIC specifies that policy actors may have veto access via changes in formal rules, informal rules or practice, which opens that channel to more variation across time and subsystems than the analogous ACF concept. Furthermore, the GIC suggests that veto possibilities are institution-specific. Policy actors who have the potential for vetoing changes to one institution (or policy) may not have similar influence over other institutions (Mahoney and Thelen 2009). Finally, the GIC highlights the conceptual importance of the targeted institution, namely the level of discretion in interpretation and enforcement, while the ACF does not acknowledge discretion as an important element, except potential as it relates to formal legal authority. Incorporating these GIC conditions would add new long-term opportunity structures to the ACF, yielding the following proposition:

Proposition 2: Changes in the political context (veto possibilities by policy actors) and/or characteristics of the targeted institution (discretion in interpretation and/or enforcement) is a necessary, but not sufficient, condition for a shift in the mode of policy change experienced in a subsystem.

This proposition explicitly draws a connection between incremental change and abrupt change, specifying the change in conditions that would be necessary for such a shift.

\section{$\underline{\text { Causal Mechanisms }}$}


Shifts in the balance of coalition resources, via coalition membership, political resources and/or access to alternative venues, are hypothesized as the main ACF causal mechanism (Nohrstedt 2011). Similarly, the GIC posits that shifts in the balance of power are an important source of institutional change, especially via mobilization of resources and coalition formation. However, the GIC further specifies that the strength of veto possibilities by institutional actors (above and beyond constitutional rules) may also influence the balance of power, suggesting a revision to Nohrstedt's (2011) proposition (revisions in bold):

Proposition 3a: Shifts in the advocacy coalition membership structure that significantly weaken the veto possibility by status quo actors increase the likelihood for more abrupt (ACF-style) policy change.

Relatedly, both frameworks highlight the potential for individual policy actors to influence policy change. The GIC places a spotlight on leadership by “change agents” who influence institutional change, positing that specific types of change agents will be associated with the various modes of change (Mahoney and Thelen 2009), while the ACF acknowledges a potential role for "policy brokers" who facilitate learning and inter-coalition agreement (Ingold 2011; Sabatier and Jenkins-Smith 1993), suggesting an additional proposition:

Proposition 3b: A dominant change agent(s) who seeks to eliminate an institution/policy and who does not follow the institution/policy rules increases the likelihood of abrupt (ACF-style) policy change.

Integrating the GIC and the ACF leverages mutual conceptual elements related to coalition structure and subsystem leadership, thus offering a richer explanation for observed policy changes.

\section{$2.4 \quad$ A Modified Framework}

Discussion of the theoretical implications of integrating the GIC and the ACF can be incorporated into the ACF visual introduced earlier in this section. Figure 5 presents a modified ACF, with revisions shown in bold. The modifications add the two main elements of institutional change (target institution and veto possibilities) and identify gradual institutional change as a potential pathway to policy change. 


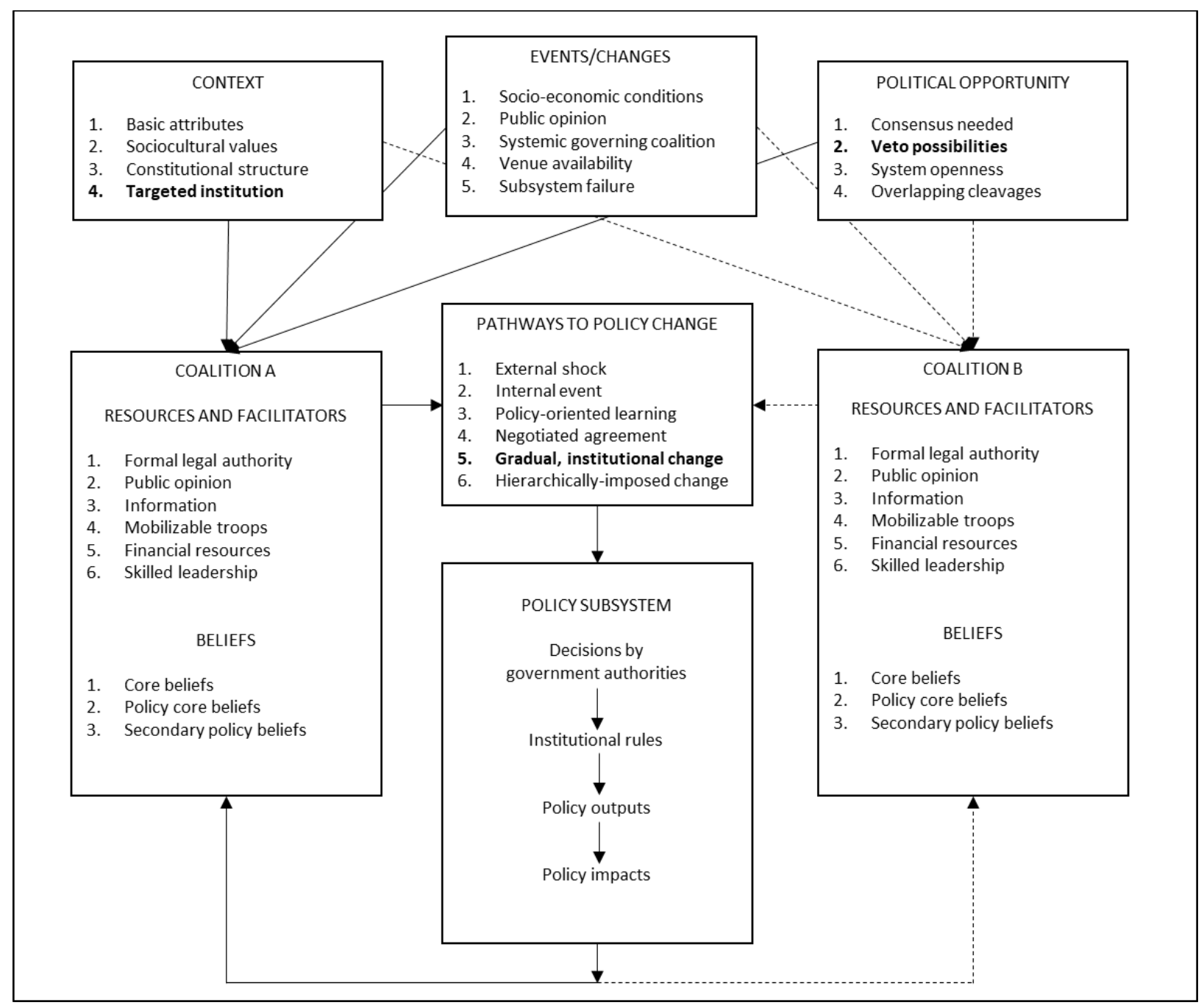

Figure 5: The Advocacy Coalition Framework, adapted from Jenkins-Smith et al. (2017), proposed revisions in bold

Despite selected differences, the two theories are epistemologically, methodologically and conceptually compatible. Both frameworks are focused on explaining changes in institutional outputs, confined to policy outputs in the case of the ACF and acknowledge the cyclical nature of the policy process. The GIC and the ACF both acknowledge the role of both institutions and actors, without taking a hard stance, although it could be argued that the ACF is more interested in activity by policy actors and the GIC focuses more heavily on the institutions that influence those actors. That said, Mahoney and Thelen (2009) clearly articulate that change agents are the key link between contextual characteristics and the type of institutional change. Both frameworks accommodate the influence of endogenous and exogenous sources of change, although the GIC is more focused on endogeneity, while the ACF has historically focused more heavily on exogenous events as the main source of change. 
Both frameworks acknowledge that there is more than one pathway to change, although the GIC is clearly more focused on explaining evolutionary (incremental) change, while the ACF is arguably more focused on explaining revolutionary (nonincremental) change. Furthermore, there several conceptual similarities; both acknowledge that the distribution of political resources and long-term institutional structures, matter to policy outputs. The GIC and the ACF both accommodate the potential for both endogenous and exogenous influence on institutional results, although the GIC is predominantly focused on explaining variation in institutional outputs as a function of endogenous factors (Mahoney and Thelen 2009).

Finally, the frameworks are methodologically compatible, including traditions of taking a long-term perspective on the change process and using both qualitative and quantitative data to explore the change process.

\section{An Illustration}

Since 2000, there have been a series of abrupt, major state-level disability policy changes across the country that have prioritized competitive, integrated employment (CIE) services for individuals with intellectual and developmental disabilities (I/DD) (Nord 2014). ${ }^{3}$ Known as "Employment First," the new CIE-focused policy changes occurred in two states-Pennsylvania and Washington — under a certain set of conditions, including subsystem events (e.g., subsystem breakdown), heightened political attention via strategic use of mobilization and information, and bureaucratic advocacy (Giordono 2019b). However, Giordono (2019b) also noted that the timing difference in these major policy changes associated with service provider coalition defection. Specifically, Washington State experienced early coalition defection by most service providers in favor of reform, while Pennsylvania did not. In fact, Pennsylvania service providers organized to resist proposed reform efforts in that state, placing limits on the degree of policy change, despite strong federal government guidance.

\footnotetext{
${ }^{3}$ During the 1980s and 1990s, stakeholders used the term "supported employment" to distinguish between traditional facility-based services (e.g., day habilitation, sheltered workshops) and new service options focused on services that support individuals to perform "paid work in normal, integrated business environments" (Wehman 1989, 2). The more contemporary term is "competitive, integrated employment" (CIE) and the terms are used interchangeably in this study. However, there are minor differences between the two terms. For example, contemporary CIE is typically not inclusive of "group supported employment" services (e.g., work crews and enclaves), which were accommodated and even encouraged, under supported employment strategies.
} 


\subsection{Methods}

This study uses a process-tracing approach to specify the causal mechanism associated with coalition defection in Washington State. The approach illustrates that a process of policy layering, which began in the mid-1980s and resulted in a dual-service system, was an important antecedent to the coalition defection and major policy change in the early 2000s.

The data for this illustration come from multiple sources, including telephone interviews with 20 policy actors in Washington State, extant data on DH\&E services, and state and federal policy documents, and extant literature. While the telephone interviews were focused on the period from 1999-2017, multiple stakeholders described events occurring during the 1980s and 1990s that they associated with the subsequent policy changes, which were corroborated by extant literature. Interviews were recorded, transcribed and coded using Dedoose 7.0. Relevant interview data, selected data from the policy documents and extant data, as well as evidence from previous studies of the subsystem, were catalogued in the form of causal process observations (Mahoney 2012).

Process-tracing is a method for studying the causal mechanisms that lead to an outcome of interest in a single case (Beach and Pedersen 2013; Collier 2011; Mahoney 2012). In this illustration, theory-building process-tracing is used to identify the causal mechanism that led to coalition defection in the selected case. The steps of theory-building process tracing include 1) conceptualization of the causal mechanism; 2) operationalization of the causal mechanisms; and 3) evidence collection.

While theory-building process tracing is often inspired by an underlying theoretical framework, it is inherently an exercise that relies on examining empirical data. In this study, the endeavor is inspired by the proposed expansion of the Advocacy Coalition Framework. Processtracing permits inferences about the presence of the causal mechanism in the selected case but does not allow for generalization to the broader population in the absence of comparative analysis. The remainder of this section describes the events in Washington State in the context of the extended ACF.

\subsection{Washington State: From Layering to Displacement}

The events in Washington State underscore the potential for incremental policy change to influence coalition membership, ultimately yielding more abrupt and major policy change years 
later. Process tracing analysis suggests the presence of a five-part causal mechanism (layering) leading to widespread adoption of the new strategy, discarding of the old strategy and eventually, coalition defection. Figure 6 depicts the five parts of the layering process, including: 1) early innovation of the new strategy (i.e., CIE services); 2) collective promotion by champions; 3) government support for adoption; 4) new and successful adoption; 5) discontinuation of the old strategy; and finally, 6) formal declaration of coalition defection. 


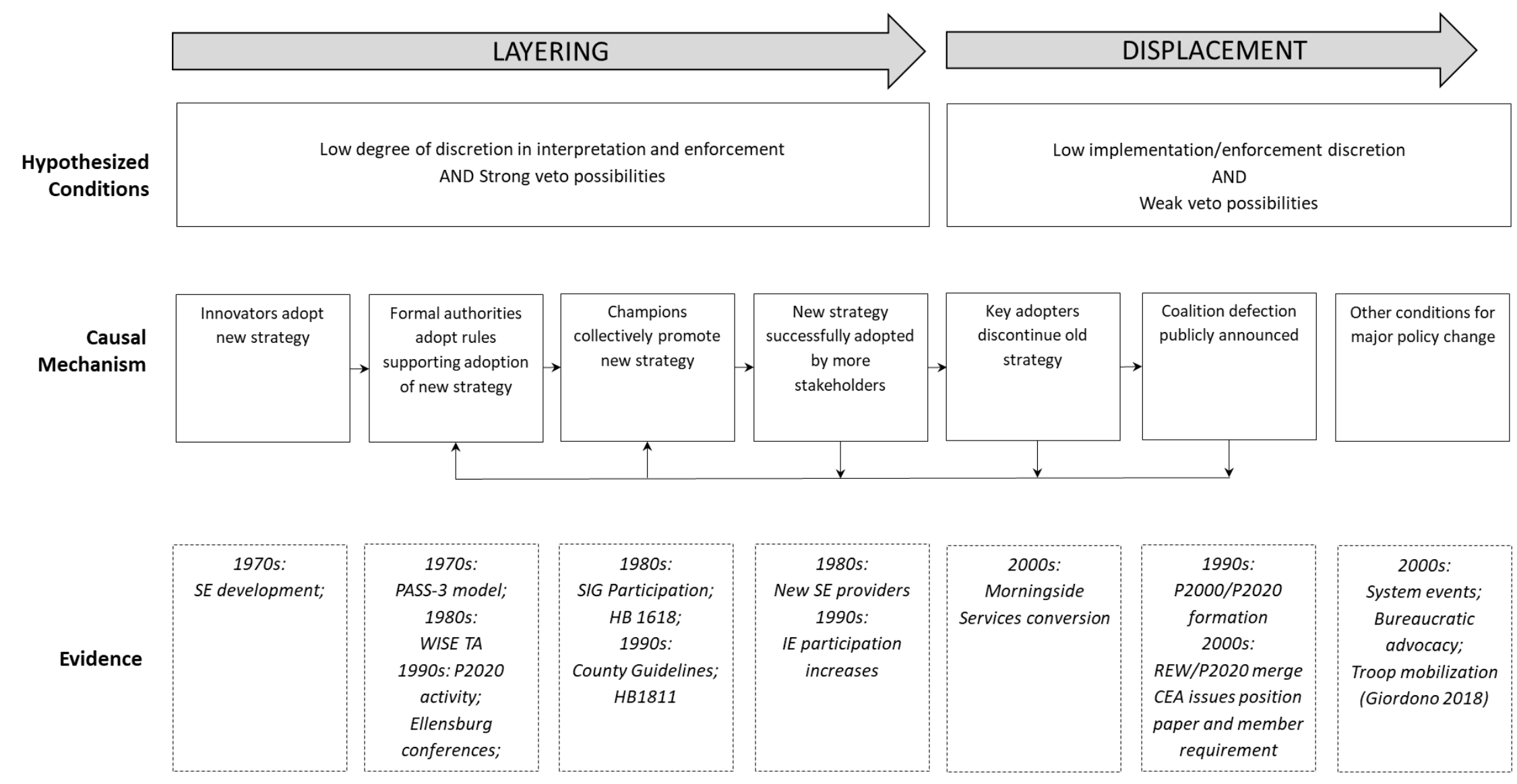

Figure 6: The Path to Coalition Defection in Washington State 
The first five steps are indicative of the layering process initially described by Streeck and Thelen (2005), in which new policy is adopted without amending older policies. The last two steps in the process, which more publicly signaled the decline in support for the dual-service system, paved the way for the development of the major policy changes that occurred in the 2006 policy directive and 2011 legislation.

The causal mechanism identified in this case begins with early adoption of a new strategy (in this case, supported employment) by a small number of innovators. In the 1970s and early 1980s, day habilitation and facility-based employment (i.e., sheltered workshops) were widespread. However, Washington service providers began to experiment with employmentbased services as early as the 1970s, and early successes with supported employment were disseminated to other service providers via PASS-3, a conciliation-based program of program evaluation (Winsor et al. 2006; Wolfensberger and Glenn 1975).

The initial innovation period was followed by a cyclical process of government intervention, strategic communication, and new adoption of supported employment strategies without changes to rules governing sheltered workshops and other facility-based services. In 1985, for example, Washington State participated in the first competitive federal Systems Innovation Grant (SIG), which provided resources for states to modify existing adult day habilitation programs, such that supported employment could be offered to participants as an alternative option (Wehman, Kregel, and Shafer 1989). The SIG was a major federal initiative that ultimately served all but two states by the late 1990s, but Washington State was part of the first cohort (Mcgaughey and Mank 2001; Wehman, Kregel, and Shafer 1989). As part of that grant, the Washington Initiative for Supported Employment (WISE) was created to provide technical assistance and training to service providers. By 1988, almost 50 new supported employment providers had been established (Wehman, Kregel, and Shafer 1989). Subsequently, in 1988, the Washington State legislature recodified the statutory authority for I/DD services (HB1618), explicitly articulating that "a pattern of facilities and services should be established... which is sufficiently complete to meet the needs of each person with a developmental disability regardless of age or degree of handicap, and at each stage of the person's development" (Substitute HB1618 1988, 770). The bill includes employment services as an example of authorized services but does not articulate a preference for either facility-based services or supported employment services. 
The cyclical process continued throughout the late 1980s and 1990s, as efforts to promote supported employment via government intervention continued in Washington State. Statesponsored conferences at Ellensburg WA provided opportunities for stakeholders, including service providers, to gather to learn about and promote supported employment (Winsor et al. 2006). The major service provider membership organization, Rehabilitation Enterprises of Washington (REW) was founded in 1974 and largely represented sheltered workshop providers at that time (Community Employment Alliance n.d.; Giordono 2019b). However, in 1992, a group of service providers committed to supported employment formed a provider network called Partnership 2000 (P2000), which they used as a platform for promoting integrated employment(Community Employment Alliance n.d.). P2000 has been credited with promoting the passage of legislation promoting the creation of supported employment opportunities within state agencies, as well as defeat of legislation that would have reduced supported employment opportunities (Winsor et al. 2006). During that same year, the Washington State Division of Developmental Disabilities produced a document called the “County Guidelines,” which articulated six primary benefits expected to result from the services, which were (and are) managed at the county level, and highlighted the role of competitive, integrated employment in achieving those benefits. After the five-year SIG grant ended, WISE transitioned into a 501(c)3 organization that continued to receive contracts from the state to support and promote the adoption of supported employment services among service providers (Giordono 2019b).

Washington State achieved relatively high rates of participation in integrated employment services during the 1990s, hitting a maximum of 58\% in 1999 (statedata.info n.d.). Despite that success, or perhaps because of it, the subsystem began to manifest signs of breakdown, including formal government reviews, a legislated stakeholder workgroup, and multiple lawsuits, as documented by (Giordono 2019b). The last steps in the defection process involved the public renouncement of the dual-service model by most major service providers. In 2004, Morningside Services, a large service provider, fully transitioned from a sheltered workshop program to integrated employment services (Community Employment Alliance n.d.; Giordono 2019b). In 2009, Rehabilitation Enterprises of Washington merged with P2020 4 to form the Community Employment Alliance (CEA), and produced a position paper that declared CIE-focused services and policy, as well as a requirement for members to pledge their support for CIE-focused values

\footnotetext{
${ }^{4}$ In 1999, Partnership 2000 was renamed Partnership 2020, or P2020 (Community Employment Alliance n.d.).
} 
(Giordono 2019b). The few CEA members who did not agree with the new vision left the organization and continued to operate as a much smaller, competing Choice coalition (Giordono 2019b).

\section{4. $\quad$ Findings}

The Working Age Adult Policy of 2006 via policy directive (and 2011 legislation) limited access to more traditional facility-based services, representing a distinct retreat from the dual-service system. Importantly, the Working Age Adults Policy fulfills the ACF concept of major change, as it represents a change in the policy core and related beliefs. However, it does not represent a full breakdown and replacement of preceding policy, as it did not fully eliminate other service options, and it was followed by subsequent minor and major policy changes (Giordono 2019b). These events suggest that the subsystem's policy change process, while aligned with the ACF, is perhaps better described as a process of layering followed by displacement, with coalition defection serving as the primary causal mechanism for the transition between the two modes.

The evidence suggests that coalition defection was the culmination of a longer-term and incremental process of policy change, which, in combination with the other short-term conditions experienced by the subsystem, including system breakdown, bureaucratic advocacy and troop mobilization (Giordono 2019b), were sufficient to bring about those policy changes. These findings offer evidence in support of Proposition 1a, although Proposition 1b cannot be tested in the absence of a comparative or frequentist research design.

Furthermore, Mahoney and Thelen (2009) posit that layering is likely to occur under conditions of 1) low discretion regarding implementation and enforcement of the targeted institution; and 2) strong veto possibilities. The services in Washington State are provided under a strong federal system responsible for issuing conditions and guidance, state guidance and a system of local contracting and management by county agencies. While there were substantial opportunities for innovation of new services, more traditional services were likely to have been subject to strict implementation and enforcement conditions. Furthermore, the strong veto possibilities of the earlier era, reflect the higher levels of service provision and participation in traditional services, which gradually shifted over time. Indeed, the shift in the balance of support for a dual-service system, which occurred in the early 2000s, also represents the shift from strong 
to weak veto possibilities, thus opening the way to displacement, and substantiating Propositions 2 and 3a.

Finally, Mahoney and Thelen (2009) hypothesize that specific types of change agents are likely to be involved with different types of institutional change. In Washington state, respondents clearly describe subsystem leadership during the layering era, especially from the 1970s through the early 1990s, as “visionary,” but rarely describe them as revolutionary. In contrast, the Director of the Department of Developmental Disabilities was described repeatedly by stakeholders as seeking to replace the traditional dual-service model with an employmentfocused model, although she was not described as a rule-breaker (Giordono 2019b). This offers mixed evidence for the change agent hypotheses forwarded by the GIC, and relatedly, Proposition 3b.

A strength of the identified causal mechanism is the ability to accommodate multiple necessary elements of the change process. For example, a simple response to demand and/or collective action by individuals and families, are embedded as "success" of the new strategy as a necessary part of the causal mechanism; in the absence of it, coalition defection is unlikely to occur. Similarly, the ACF pathway of policy-oriented learning is also consistent with these results, and is embedded in early policy changes, which emphasized technical assistance and training to service providers.

Process tracing methods, when, used in a single case, are intended to be used to specify parts of a causal mechanism, make within-case inferences about the mechanism and contribute to the development of generalizable theories (Beach and Pedersen 2013). While the ACF is a powerful explanatory tool, the GIC extension augments the explanation with insights about 1) the character of the earlier era; and 2) the transition from one type of policy change to the other. The illustration offers strong evidence of a shift from layering to displacement and supports the proposed extension of the ACF. Furthermore, it suggests that coalition defection and bureaucratic advocacy may function as signals of an upcoming shift in the mode of change. The results are aligned with the ACF but offer a richer explanation of antecedents to the major policy changes that occurred in that subsystem. That said, comparative analysis is needed to more broadly test the propositions, suggesting potential steps for future research. 


\section{Discussion and Conclusion}

For us it is an important question to what extent the fringe and the core can peacefully coexist, or whether the fringe can attract enough defectors from the core eventually to displace it.

(Streeck and Thelen 2005, 24)

The above sentiment is strikingly aligned with the ACF research agenda established by Sabatier and Jenkins-Smith (1988). The opportunity to unite the two frameworks stems in part from their attention to different manifestations of the dependent variable, policy change, whereby the ACF is more concerned with explaining abrupt (and discontinuous) change, while the GIC is focused on explaining incremental (and discontinuous) change. ${ }^{5}$

This study's objectives were to 1) to identify strategies for using concepts from the GIC in the context of the ACF; and 2) to demonstrate the value of an extended framework using an empirical illustration. Both objectives were met, with limitations. The extended framework will benefit from continued efforts to refine concepts and test propositions. The value of the illustration is limited by methodological choices, including the decision to focus on a process study, rather than a comparative study. The illustration is also limited to an analysis of a layering/displacement process, while the GIC proposes several forms of incremental change, which might manifest very differently (or not at all) in the context of the ACF. However, it demonstrates the applicability of GIC concepts and hypotheses to a single case and shows the potential for the GIC to offer a richer understanding of major policy change to ACF applications.

Extending the ACF to accommodate the GIC provides a richer explanation for policy change, yields insights into causal mechanisms, and is likely to expand its scope to subsystems that experience major, incremental change over a longer time horizon. The ACF is applied most heavily in environmental and energy subsystems (Pierce et al. 2017), which may be less likely to accommodate dual-tracked systems due to the nature of conflict and coalition activity in subsystems where common pool resources and property rights are contested. In contrast, social policy systems, which are constrained by financial resources and political will, may be more likely to accommodate gradual, institutional change. An extended framework may also open avenues to examining cases in which policy change appears to be lacking, despite conditions that

\footnotetext{
${ }^{5}$ Admittedly, the GIC takes a broader view of the dependent variable than the ACF. The focus on policy change is the ACF's primary focus, but only a subset of the GIC's interest in institutional change more broadly.
} 
would otherwise be expected to yield major change. Finally, extending the ACF with the GIC may provide a template for gaining a richer understanding of policy change that can be applied to other policy process frameworks, such as the Narrative Policy Framework (NPF) and Policy Conflict Theory (PCT), both of which are theoretically and epistemologically aligned with the ACF.

From a policymaker's perspective, an extension to an existing theoretical framework is unlikely to yield substantial added value for their everyday work. However, the application of such a framework to a variety of settings is likely to provide new insights into the policy process, inclusive of policy formation, adoption and implementation. The illustration in this study, for example, suggests that coalition defection and bureaucratic advocacy may signal of an upcoming shift in the type of policy change pursued by coalitions. While such observations are unlikely to be novel for an astute policymaker, they may nevertheless inform strategic advocacy efforts, and prepare policymakers for other shifts in subsystem characteristics, such as the level of conflict. Finally, the findings highlight the potential for differential policy paths to influence the timing of subsequent policy decisions; overcoming such differences, if desired, may require targeted investments in straggling jurisdictions.

This study offers several opportunities for future research. The illustration, while informative, invites additional comparative analysis, preferably to a sample that moves beyond the two-case study conducted by (Giordono 2019b). A similar study of a larger sample over a longer timeframe (e.g., starting in 1980) would provide an opportunity to test some of the propositions and the overall model. Furthermore, comparative applications in other subsystems that are likely to exhibit gradual, transformative change will offer fruitful opportunities for advancing the proposed integration. Applications to subsystems that have been shown to experience other forms of gradual institutional change, such as the drift experienced in the US welfare state (Hacker 2005), would also be fruitful.

Finally, the illustration highlights the potential for refinements to the dependent variable, major policy change. Giordono (2019b) uses a dichotomous variable aligned with typical ACF applications to identify major/minor policy change. However, that study also notes the multiple junctures (and venues) in which similar major policy changes occur in both Washington and Pennsylvania, suggesting that the time horizon of the policy change outcome may be more aligned with a GIC-style incremental displacement process than the typical ACF-style abrupt 
change. Multiple authors have described a "dependent variable problem” associated with conceptualizing and operationalizing policy change (e.g., Green-Pedersen 2004; Howlett and Cashore 2009; Spicker 2018). Perhaps an extended framework, and closer connections between the policy process and comparative politics traditions, provides a dependent variable opportunity. 


\section{References}

Beach, Derek, and Rasmus Brun Pedersen. 2013. Process-Tracing Methods: Foundations and Guidelines. 1st edition. Ann Arbor: University of Michigan Press.

Collier, David. 2011. “Understanding Process Tracing.” PS: Political Science and Politics 44(4): 823-30.

Community Employment Alliance. n.d. “Community Employment Alliance: About Us.” Marcie Taylor. http://communityemploymentalliance.org/services.html (March 26, 2018).

Giordono, Leanne S. 2019a. “Advocacy Coalitions in Low Salience Policy Subsystems: Struggles Under a Smooth Surface.” Policy Studies Journal 0(0).

https://onlinelibrary.wiley.com/doi/abs/10.1111/psj.12330 (April 9, 2019).

—. 2019b. From Employment Optional to "Employment First": Explaining Two Cases of StateLevel Disability Policy Change. Open Science Framework. preprint. https://osf.io/zqpex.

Green-Pedersen, Christoffer. 2004. "The Dependent Variable Problem within the Study of Welfare State Retrenchment: Defining the Problem and Looking for Solutions.” Journal of Comparative Policy Analysis: Research and Practice 6(1): 3-14.

Hacker, Jacob S. 2005. "Policy Drift: The Hidden Politics of US Welfare State Retrenchment.” In Beyond Continuity: Institutional Change in Advanced Political Economies, New York, NY, USA: Oxford University Press.

Howlett, Michael, and Benjamin Cashore. 2009. “The Dependent Variable Problem in the Study of Policy Change: Understanding Policy Change as a Methodological Problem.” Journal of Comparative Policy Analysis: Research and Practice 11(1): 33-46.

Ingold, Karin. 2011. "Network Structures within Policy Processes: Coalitions, Power, and Brokerage in Swiss Climate Policy.” Policy Studies Journal 39(3): 435-59.

Jenkins-Smith, Hank, Daniel Nohrstedt, Christopher M. Weible, and Karin Ingold. 2017. “The Advocacy Coalition Framework: An Overview of the Research Program.” In Theories of the Policy Process, eds. Christopher M. Weible and Paul A. Sabatier. Boulder, CO: Westview Press, 183-224.

Koebele, Elizabeth A. 2019. "Integrating Collaborative Governance Theory with the Advocacy Coalition Framework.” Journal of Public Policy 39(1): 35-64.

Kübler, Daniel. 2001. "Understanding Policy Change with the Advocacy Coalition Framework: An Application to Swiss Drug Policy.” Journal of European Public Policy 8(4): 623-641.

Mahoney, James. 2012. “The Logic of Process Tracing Tests in the Social Sciences.” Sociological Methods \& Research 41(4): 570-97.

Mahoney, James, and Kathleen Thelen. 2009. Explaining Institutional Change: Ambiguity, Agency, and Power. Cambridge University Press.

McBeth, Mark K., Elizabeth A. Shanahan, Ruth J. Arnell, and Paul L. Hathaway. 2007. "The Intersection of Narrative Policy Analysis and Policy Change Theory.” Policy Studies Journal 35(1): 87-108. 
Mcgaughey, Martha, and David Mank. 2001. “Empirical Evidence of Systems Change in Supported Employment.” Journal of Disability Policy Studies 11(4): 210-222.

Nohrstedt, Daniel. 2011. "Shifting Resources and Venues Producing Policy Change in Contested Subsystems: A Case Study of Swedish Signals Intelligence Policy.” Policy Studies Journal 39(3): 461-84.

Pierce, Jonathan J. et al. 2017. “There and Back Again: A Tale of the Advocacy Coalition Framework.” Policy Studies Journal 45(S1): S13-46.

Sabatier, Paul A., and Hank C. Jenkins-Smith. 1993. Policy Change and Learning : An Advocacy Coalition Approach. Boulder, Colo: Westview Press.

Sabatier, Paul A., and Christopher M. Weible. 2007. "The Advocacy Coalition Framework: Innovations and Clarifications.” In Theories of the Policy Process, ed. Paul A. Sabatier. Boulder, CO: Westview Press, a member of the Persus Books Group, 189-222. http://200.41.82.27/108/1/Sabatier,\%20Paul,\%20Weible\%20C_The\%20Advocacy\%20Coalition \%20Framework.\%20Innovations\%20and.pdf (November 8, 2017).

Shanahan, Elizabeth A., Michael D. Jones, and Mark K. McBeth. 2011. "Policy Narratives and Policy Processes.” Policy Studies Journal 39(3): 535-61.

Spicker, Paul. 2018. “The Real Dependent Variable Problem: The Limitations of Quantitative Analysis in Comparative Policy Studies: The Real Dependent Variable Problem: The Limitations of Quantitative Analysis in Comparative Policy Studies.” Social Policy \& Administration 52(1): 216-28.

Streeck, Wolfgang, and Kathleen Thelen. 2005. "Introduction: Institutional Change in Advanced Political Economies.” In Beyond Continuity: Institutional Change in Advanced Political Economies, eds. Wolfgang Streeck and Kathleen Thelen. New York, NY, USA: Oxford University Press, USA.

Wehman, Paul, John Kregel, and Michael Shafer. 1989. "Emerging Trends in the National Supported Employment Initiative: A Preliminary Analysis of Twenty-Seven States.” https://eric.ed.gov/?id=ED322660 (October 1, 2018).

Weible, Christopher M., and Tanya Heikkila. 2017. "Policy Conflict Framework.” Policy Sciences. http://download.springer.com.ezproxy.proxy.library.oregonstate.edu/static/pdf/434/art\%253A10.1 007\%252Fs11077-017-92806.pdf?originUrl=http\%3A\%2F\%2Flink.springer.com\%2Farticle\%2F10.1007\%2Fs11077-01792806\&token2=exp=1488226668 acl=\%2Fstatic\%2Fpdf\%2F434\%2Fart\%25253A10.1007\%25252Fs 11077-017-9280-

6.pdf\%3ForiginUrl\%3Dhttp\%253A\%252F\%252Flink.springer.com\%252Farticle\%252F10.1007 \%252Fs11077-017-9280-

6* hmac $=$ ed29d6c7e58f2c06784b9bf63bb63e1ba1510605408279409c41c0533554970d (February 27, 2017).

Winsor, Jean E., Allison Cohen Hall, John Butterworth, and Dana Scott Gilmore. 2006. Pushing the Integrated Employment Agenda: Case Study Research in Washington State. http://www.communityinclusion.org/article.php?article_id=173 (May 2, 2017). 
Wolfensberger, Wolf, and Linda Glenn. 1975. "Program Analysis of Service Systems (PASS 3): A Method for the Quantitative Evaluation of Human Services (Handbook).” Books: Wolfensberger Collection. https://digitalcommons.unmc.edu/wolf_books/2. 